\title{
Takım Sporu ile Bireysel Spor Yapan Öğrencilerin Sezinleme Zamanlarının İncelenmesi
}

\section{Investigation of Anticipation Time in Students Participating in Team and Individual Sports}

\author{
Araştırma Makalesi
}

${ }^{1}$ Mehmet Kadir AKBULUT, ${ }^{2}$ Işıl AKTAĞ, ${ }^{3}$ Selçuk AKPINAR

1 Kanuni Sultan Süleyman Ortaokulu, Belen, Hatay

2 Beden Eğitimi ve Spor Yüksekokulu, Bolu Abant İzzet Baysal Üniversitesi, Bolu

3 Beden Eğitimi ve Spor Eğitimi Bölümü, Eğitim Fakültesi, Nevşehir Hacı Bektaş Veli Üniversitesi, Nevşehir

\section{$\ddot{0} z$}

u çalışma Hatay ilinde okul sporlarına katılan ortaokul 7. ve 8. sınıf takım sporu (basketbolhentbol) ve bireysel spor (masa tenisi-badminton) yapan öğrencilerin sezinleme zamanlarının incelenmesi amacı ile yapılmıştır. Araştırmaya 2011-2012 eğitim-öğretim yılında Hatay ilinde okul sporlarına katılan okullardan 116 erkek, 121 kız öğrenci gönüllü olarak katılmıştır. Araştırma verileri, Lafayette Enstitü tarafından geliştirilen Bassin Anticipation Timer cihazı ile toplanmıştır. Verilerin çözümlenmesinde SPSS (17.0) kullanılarak, takım sporu yapan öğrenciler ile bireysel spor yapan öğrencilerin gruplar arasında, cinsiyete göre, spor deneyimine göre ve yaşa göre sezinleme zamanları arasında fark olup olmadığı incelenmiştir. Verilerin analizinde $t$ testi veya tek yönlü Anova Testi kullanılmıştır. Sonuçlara bakıldığında, bireysel spor yapan öğrencilerin daha iyi sezinleme zamanına sahip oldukları ortaya çıkmıştır. Kız öğrencilerle erkek öğrenciler arasında ve yaşlar (12-13-14) arasında sezinleme zamanında anlamlı fark elde edilmemiştir. Öğrencilerin spor deneyimlerine göre sezinleme zamanları arasındaki farklılıklara baktığımızda, 1 yıldır spor yapan öğrencilerin sezinleme zamanlarının 2 (iki),

\section{A B S TRACT}

The purpose of this study was to investigate the anticipation time of 7 th -8 th grade middle school students who were participating team sports (basketball and handball) and individual sports (table tennis and badminton) in Hatay. 116 male and 121 female middle school students, who were attending school sports in Hatay in 2011-2012 education years, were participated in this study. Bassin Anticipation Timer, which was developed by Lafayette Institute, was used to measure anticipation time. It was investigated that whether anticipation time was differed between the students who participated team sports (basketball and handball) and individual sports (table tennis and badminton), between genders, between sport experience, and between ages. One Way Anova and test were used to analyze the data. Statistical analysis revealed a significantly better performance of anticipation time in favor of students who participated individual sports compared to team sports. Whereas, the results for age and gender displayed no significant differences in anticipation time, the effect of sport experience on anticipation time was found to be significant. Students who had 1 year of sport experience got significantly worse anticipation time performan- 
3 (üç) ve 4 (dört) yıldır spor yapan öğrencilere göre daha yüksek olduğu bulunmuştur. Bu sonuçlara göre, bireysel sporlarda sezinleme zamanının takım sporlarına göre daha önemli olabileceği ve spor deneyiminin artması ile sezinleme zamanında gelişme olabileceği söylenebilir.

\section{Anahtar Kelimeler}

Motor Performans, Sezinleme, Sezinleme Zamanı, Takım Sporu, Bireysel Spor.

\section{GiRiş}

Spor alanında başarılı olabilmek için fiziksel yeterliliklerin yanı sıra algısal yeterliliklere de intiyaç duyulmaktadır. Bütün sporlarda becerilerin etkili ve verimli yapılabilmesi için üst düzey algısal yeteneklere ihtiyaç vardır (Mori ve diğ., 2002). Sezinleme zamanı da bu algısal yeteneklerden birisi olarak karşımıza çıkmaktadır (Akpınar ve diğ., 2012). Sezinleme zamanı genel olarak herhangi bir rota izleyen obje veya nesnenin sonlanma noktasını ve bu noktaya ne zaman geleceğini tahmin etme yeteneği olarak tanımlanmaktadır (Williams ve diğ., 2000). Sezinleme zamanı, genellikle el-göz koordinasyonunun test edilmesi ve bunun görsel doğruluğundaki tahmininde kullanılmaktadır (Williams ve diğ., 2000).

McMorris (2004)'e göre motor becerilerde 2 çeşit sezinlemeden bahsedilmektedir. Algısal sezinleme ve kesik becerilerdeki sezinleme (rastlantısal-sezinleme). Algısal sezinleme daha çok kişinin sezinleme zamanını düşünmesini içerirken, kesik beceriler ise, bir objeyi yakalama, vurma veya atma gibi hareketleri içerir. Rastlantısal sezinleme zamanı ise yine kendi içerisinde ikiye ayrılmaktadır. Bunlar efektör ve reseptör sezinlemedir. Efektör sezinleme, kişinin herhangi bir vücut parçasını ne kadar sürede hareket ettireceğini tahmin etme yeteneği olarak tanımlanırken, reseptör sezinleme ise dışsal bir olayın ne kadar sürede gerçekleşeceğini belirleme olarak tanımlanır. Örneğin, top yakalama sırasında topun havada ne kadar mesafe ve süre kat edeceği tahmin edilir (reseptör sezinleme) ve buna göre ellerin ne zaman topu tutma için vücudun önüne getirileceği hesaplanır (efektör sezinleme).

Topla oynanan sporların hepsinde bu algısal ce compared to 2, 3, and 4 years of sports experience. In conclusion, anticipation time can be more essential in individual sports compared to team sports and can be developed with the sport experience.

\section{Key Words}

Motor Performance, Anticipation, Anticipation Time, Individual Sports, Team Sports.

yetenek başarılı bir performans için önemli parametrelerden biri olarak görülmektedir (Magill, 2004; Schmidt ve Lee, 2005). Örneğin; raket sporlarında topun hareketini gözlemlemek, takip etmek, topun varacağı noktayı tahmin etmek ve en sonunda topu karşı sahaya göndermek gereklidir. Bu noktada, topun ulaşacağı noktanın tahmin edilmesinde sezinleme zamanı önemli bir rol oynamaktadır (Magill, 2004; Schmidt ve Lee, 2005). Bunun yanında basketbol veya hentbol gibi takım sporlarında koşu halinde olan takım arkadaşına pas verme sırasında pası atacak olan oyuncunun takım arkadaşının koşu hızını tahmin ederek topu koşu yoluna atması ve onunla buluşturması yine sezinleme zamanı gerektirmektedir. Bundan dolayı, bu algısal yeteneğin belirli aralıklarla test edilmesi ve değişikliklerin izlenmesi sporcuların gelişimi ile ilgili önemli bilgiler sağlayacaktır. Sezinleme zamanı özellikle sporcuların test edilmesinde ve yetenekli bireylerin seçilmesinde uzun yıllardır kullanılmaktadır (Ripoll ve Latiri, 1997). Birçok çalışmada deneyimli sporcuların deneyimsiz olan sporculara göre daha doğru sezinleme zamanına sahip oldukları tespit edilmiştir (Lyons ve diğ., 2008; Tenenbaum ve diğ., 2000; Williams ve Starkes, 2002).

Sezinleme zamanı ile ilgili literatürdeki çaışmalara bakıldığında araştırmaların genellikle cinsiyet (Ak ve Koçak, 2010; Brady, 1996; Dede, 2010; Söğüt ve diğ., 2009), yaş (Dede, 2010; Kuhlman ve Beitel, 1987), beceri düzeyleri (Dede, 2010) arasındaki farklılıklara odaklandıkları görülmektedir (DelVillar, Gonzalez ve diğ., 2007; Lyons ve diğ., 2008; Rowe ve McKenna, 2001; Tenenbaum ve diğ., 2000; Williams ve Starkes, 2002). 
Cinsiyet ile ilgili çalışmalara bakıldığında bazı çalışmalarda erkeklerin kadınlara göre daha iyi sezinleme zamanına sahip oldukları bulunurken (Ak ve Koçak, 2010; Brady, 1996; Kuhlman ve Beitel, 1987; Söğüt ve diğ., 2009), diğer bir çalışmada, erkek ve kadınlar arasında sezinleme zamanında fark bulunamamıştır (Dede, 2010).

Erkeklerin kadınlara göre daha iyi sezinleme zamanına sahip olduklarını belirten çalışmalarda bunun sebebinin yapılan işle (ölçülen hareketle) ilgili zorluktan kaynaklandığı belirtilmektedir (Sanders, 2011). Erkeklerin özellikle kolay olan becerilerde avantajlı oldukları, beceri zorlaştıkça kadın ve erkek arasındaki farklılığın azaldığı tespit edilmiş̧ir (Petrakis, 1985; Sanders, 2011).

Literatürdeki çalışmalara bakıldığında, spor deneyimi ifadesi farklı içeriklerle kullanılmıştır. Kuhlman ve Beitel (1987) spor deneyimini, sporcuların toplamda katıldıkları yarış sayısı ile belirlerken, Söğüt ve diğ. (2009) sporcuların sadece yarışmacı olmalarının yeterli olacağını ifade etmiş, Mori ve diğ. (2002), Akpınar ve diğ. (2010) ve Dede (2010) ise toplamda sporcuların ne kadar süre spor yaptıklarını dikkate alarak çalışmalarına yön vermişlerdir.

Sezinleme zamanı ile ilgili araştırmalarda deneyimli ve deneyimsiz sporcular arasındaki farka bakılmıştır. Deneyimin etkisini araştıran çalışmalarda da genel olarak deneyimli sporcuIarın daha iyi bir sezinleme zamanına sahip oldukları bulunmuştur (Lyons ve diğ., 2008; Mori ve diğ., 2002; Tenenbaum ve diğ., 2000; William ve Starkes, 2002).

Williams (1985)'te yaptığı çalışmasında; yaşla birlikte sezinleme zamanı performansının arttığı, diğer bir deyişle yapılan hataların deneyimle birlikte paralel olarak azaldığını ortaya koymuştur.

Sezinleme zamanı ile ilgili çok sayıda çalışma yapılmış olmasına rağmen, bireysel ve takım sporlarında sezinleme zamanı farklılıklarını inceleyen çok fazla çalışma bulunmamaktadır. Söğüt ve diğ. (2009) masa tenisi ve tenis sporcularında sezinleme zamanını incelemiş ve tenis oyuncularının daha iyi sezinleme zamanı performansına sahip olduğunu belirlemişlerdir. Ak- pınar ve diğ. (2012)'de; masa tenisi, badminton ve tenis sporcularının farklı sezinleme zamanlarına sahip olduklarını ortaya koyarken, uyarının akış hızı yavaş olduğunda tenis sporcularının, orta düzey olduğunda badminton sporcularının, yüksek olduğunda ise masa tenisi sporcularının sezinleme zamanları daha iyi olduğu gözlemlenmiştir. Diğer bir çalışmada basketbol, voleybol ve su topu sporcularının yine farklı sezinleme zamanına sahip oldukları belirlenmiştir (Kioumourtzoglou ve diğ., 1998). Sezinleme zamanının özellikle farklı spor branşlarında test edilmesi, bu spor branşları ile ilgili karakteristikleri ortaya çıkaracağından önemli olduğu düşünülmektedir.

Bu çalışmanın temel amacı, takım sporu yapan (basketbol ve hentbol) ve bireysel spor yapan (masa tenisi ve badminton) ortaokul 7. ve 8. sınıf öğrencilerinin sezinleme zamanlarında farkııık olup olmadığını ortaya koymaktır. Bunun yanında spor yapan öğrencilerin sezinleme zamanlarında cinsiyete göre farklılık olup olmadığı, spor deneyiminin ve yaşın sezinleme zamanına etkisi de araştırıımıştır.

\section{YÖNTEM}

Araştırma Grubu: Bu çalışmaya Hatay ilinde okul sporlarına katılan ve okul sporlarının Badminton (56), Masa Tenisi (57), Hentbol (60) ve Basketbol (64) branşlarında yarışan 7. ve 8. sınıf öğrencilerinden toplam 237 öğrenci katılmıştır. Bu öğrenciler, 12-13-14 yaşında 121 kız ve 116 erkek öğrenciden oluşmaktadır.

Veri Toplama Araçları: Araştırmada, demografik bilgilerin yer aldığı (adı-soyadı, yaşı, sınıfı, cinsiyeti, baskın el, yapılan spor, spor deneyim yılı) bilgi formu kullanılmıştır. Sezinleme zamanını ölçmek için Dr. Stanley Bassin'in bulduğu, Lafayette Üniversitesi tarafından geliştiriIen, Bassin Anticipation Timer cihazı (Lafayette Instrument Company, Model 50575) kullanıımıştır. Bu cihazın geçerliliği ile ilgili çalışmalar bulunmaktadır. Örneğin Merwe ve Randt (1999)'da yaptıkları araştırmada laboratuvar ortamında ölçülen sezinleme zamanı ile alanda ölçülen sezinleme zamanının arasındaki farka bakmışlardır. Bu çalışmada 17 çok deneyimli zaman 


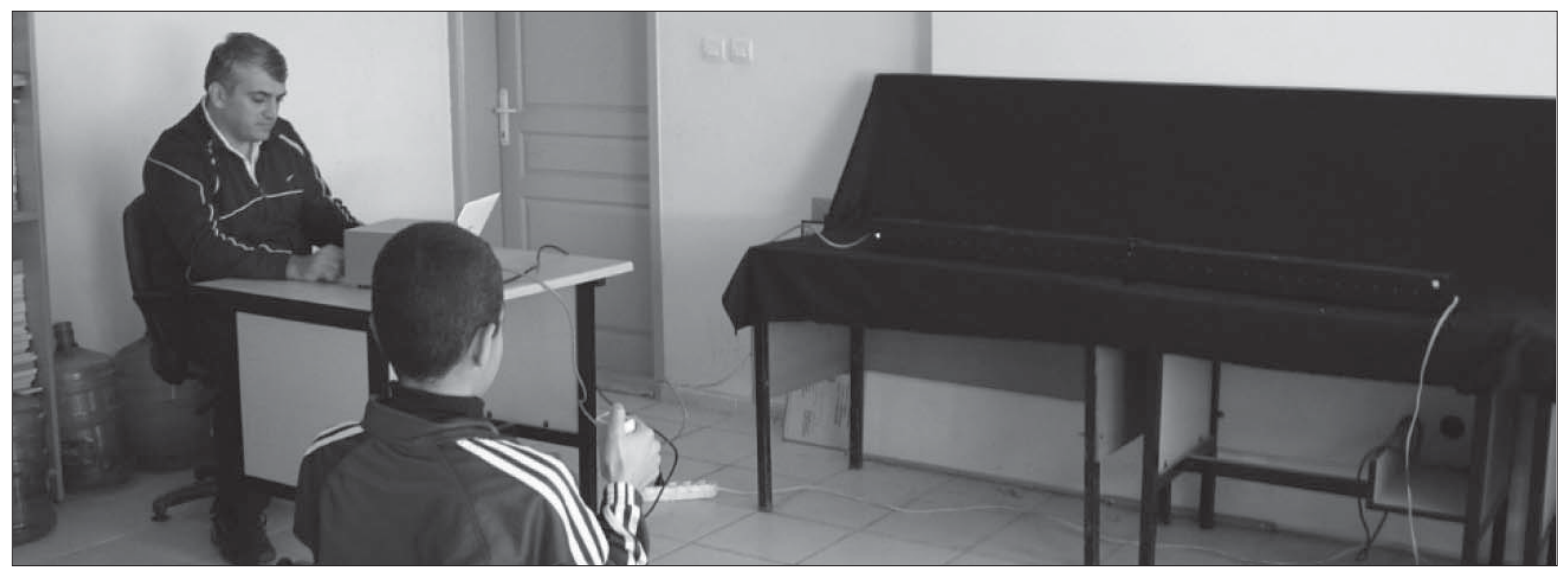

Şekil 1. Sezinleme Zamanı Öıçümü

tutan hakem yer almaktadır. Kısa mesafe koşan sprinterlerin süreleri fotosel ile hakemlerin el kronometresi ölçüm sonucu ortaya çıkan veriler, fotosel ve kronometre arasındaki süre farkı hata olarak belirlenmiştir. Ayrıca Bassin Anticipation Timer ile ölçülen sezinleme zamanı sonuçları yine hata olarak kaydedilmiştir. Zaman hakemlerinin, atletizmden elde edilen hata sonuçları ve Bassin Anticipation Timer arasındaki hata sonuçları arasında yüksek düzeyde ilişki bulunmuştur. Bu da bu aletin sezinleme zamanının ölçülmesinde geçerli olduğunu göstermektedir (Merwe ve Randt, 1999).

Verilerin Toplanması: 2011-2012 eğitimöğretim yılında Hatay ili ve ilçelerinde okul sporlarında Badminton, Masa Tenisi, Basketbol ve Hentbol branşlarında yarışan kız ve erkek öğrencilerin bulunduğu ortaokullar gezilerek toplanmıştır.

Bassin Anticipation Timer cihazı, okulun bilgisayar sınıfında, bilgisayar masasının üzerine yerleştirilerek öğrencilere tanıtılmıştır. Denek, cihaza 2.5 m uzakta sandalyeye oturur vaziyette bulunurken, sezinleme zamanı cihazı üzerindeki hareket eden ışığın, hedeflenen sonlandırma noktasında (cihazın üzerindeki son lamba) olduğu anda, eli ile kavradığı, hedefi istediği anda durdurabileceği elektronik bir düğmeye basması istenmiştir. Düğmeye basılması sonrası kontrol panelinde görülen değer forma kaydedilmiştir. Veriler toplanırken, öğrencilerden baskın (dominant) ellerini kullanmaları istenmiş ve ölçümler bu şekilde yapılmıştır. Ölçüm safha- sında, önce 5 adet deneme yapılarak öğrenciye performansı hakkında dönüt verilmiştir. Cihaz farklı hızlara göre ayarlanabilir özelliklere sahip olup, veriler 2 m/sn hızda ve 30 tekrar yapılarak (Millslagle, 2004) saniye cinsinden kayıt altına alınmıştır (Şekil 1).

Verilerin Analizi: Verilerin çözümlenmesinde t-testi, tek yönlü varyans analizi (ANOVA) ve frekans analizi teknikleri kullanılmıştır. Çalışmada anlamlılık düzeyi 0.05 olarak kabul edilmiştir. Toplanan veriler her sporcu için ayrı ayrı hesaplanırken, her bir deneme sonucunun mutlak değeri alınması sonucu, deneğin sezinleme zamanı ortalaması hesap edilmiştir. Elde edilen verilerde hatanın yönü (kumandaya önce (-) veya sonra (+) basılması ile ortaya çıkan sonuçtur ve bu sonuç negatif (-) veya pozitif (+) olabilir) değil, hatanın büyüklüğü önemli olduğundan, verilerin mutlak değeri alınarak istatistiksel olarak analize tabi tutulmuştur. Diğer bir ifadeyle, deneğin sezinleme zamanı cihazı üzerindeki hareket eden ışığın, hedeflenen sonlandırma noktasında olduğu anda kumandaya basarak, kontrol panelinde görülen değerin mutlak değeri alınarak tüm denemelerin toplanıp ortalamasının alınmasıdır. Ortaya çıkan bu değer sporcunun hatasının büyüklüğü olarak nitelendirilir.

\section{BULGULAR}

Aşağıda veri toplama araçları ile elde edilen bilgiler tablolar ve grafikler halinde sunulmuştur. Araştırma grubunun cinsiyet değişkenine göre dağılımı Tablo 1'de verilmiştir. 
Tablo 1. Araştırmaya katılan öğrencilerin cinsiyetlerine göre dağılımı

\begin{tabular}{|c|c|c|c|c|c|}
\hline \multicolumn{2}{|c|}{ Cinsiyet } & \multirow{2}{*}{$\begin{array}{r}\text { Badminton } \\
30\end{array}$} & \multirow{2}{*}{$\begin{array}{r}\text { Masa Tenisi } \\
26\end{array}$} & \multirow{2}{*}{$\begin{array}{r}\text { Basketbol } \\
34\end{array}$} & \multirow{2}{*}{$\begin{array}{l}\text { Hentbol } \\
31\end{array}$} \\
\hline & $n=121$ & & & & \\
\hline 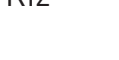 & $\%$ & 53.57 & 45.61 & 53.13 & 51.67 \\
\hline \multirow{2}{*}{ Erkek } & $n=116$ & 26 & 31 & 30 & 29 \\
\hline & $\%$ & 46.43 & 54.39 & 46.88 & 48.33 \\
\hline Toplam & & 56 & 57 & 64 & 60 \\
\hline
\end{tabular}

Araştırma grubunun yaş değişkenine göre dağılımı Tablo 2'de verilmiştir.

Tablo 2. Araştırmaya katılan öğrencilerin yaşa göre dağılımı

\begin{tabular}{ccc} 
Yaş (n=237) & $\mathbf{N}$ & \% \\
\hline 12 Yaş & 52 & 21.94 \\
\hline 13 Yaş & 108 & 45.57 \\
\hline 14 Yaş & 77 & 32.49
\end{tabular}

Araştırma grubunun spor deneyimine göre dağılımı Tablo 3'de verilmiştir.
Tablo 3. Araştırmaya katılan öğrencilerin deneyime göre dağılımı

\begin{tabular}{ccc}
\hline Deneyim $(\mathbf{n = 2 3 7 )}$ & \multicolumn{1}{c}{} \\
\hline 1 yıl & 55 & 23.21 \\
\hline 2 yıl & 89 & 37.55 \\
\hline 3 yıl & 66 & 27.85 \\
\hline 4 yıl & 27 & 11.39 \\
\hline
\end{tabular}

Takım sporu yapanlar ile bireysel spor yapanların sezinleme zamanı ortalamaları ve standart sapma değerleri Grafik 1'de verilmiştir.

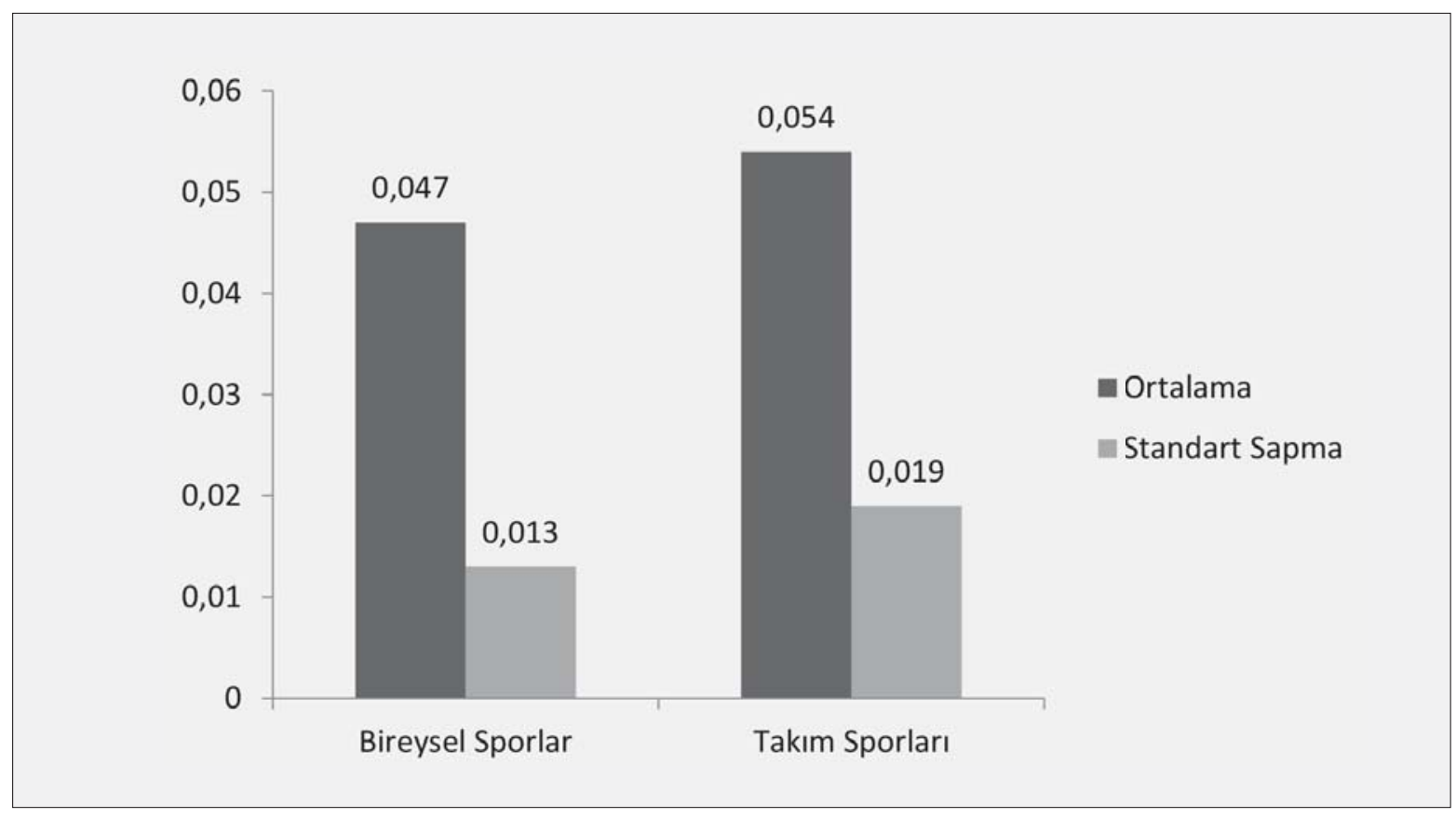

Grafik 1. Bireysel sporlar ve takım sporları sezinleme zamanı ortalama (sn) ve standart sapma değerleri 
Bireysel spor yapan (Badminton-Masa Tenisi) öğrencilerin sezinleme zamanı ortalamaları 0.047 sn. iken, takım sporu yapan (BasketbolHentbol) öğrencilerin sezinleme zamanı ortalamaları 0.054 sn. bulunmuştur. Yapılan istatistiksel analiz sonucunda, bireysel spor yapan öğrencilerin sezinleme zamanlarının takım sporu yapan öğrencilerin sezinleme zamanlarından daha iyi olduğu bulunmuştur ( $\left.\mathrm{t}_{(235)}=-3.377, \mathrm{p}=0.01\right)$.

Grafik'2 de tüm kız ve erkek öğrencilerin sezinleme zamanı ortalama (sn) ve standart sapma değerleri verilmiştir.

Araştırmaya 116 kız öğrenci, 121 erkek öğrenci katılmış olup, katılan tüm erkek öğrencilerin sezinleme zamanı ortalamaları 0.050 sn. iken, kız öğrencilerin sezinleme zamanı ortalamaları
0.051 sn. olduğu tespit edilmiş ve sezinleme zamanlarında istatistiksel olarak anlamlı fark bulunmamıştır $\left(\mathrm{t}_{(235)}=-0.388, \mathrm{p}=0.698\right)$.

Öğrencilerin spor deneyim yılına göre sezinleme zamanı ortalama (sn) ve standart sapma değerleri Grafik 3'te verilmiştir.

Spor deneyimi 1 (bir) yıl olan öğrencilerin sezinleme zamanları ortalaması 0.058 sn, 2 (iki) yıl olan öğrencilerin ortalamaları 0.049 sn, 3 (üç) yıl olan öğrencilerin ortalamaları 0,047 sn. ve 4 (dört) yıl olan öğrencilerin ortalamaları 0.046 sn. olduğu görülmektedir. Spor deneyimine göre öğrencilerin sezinleme zamanları karşılaştırıldığında, öğrencilerin sezinleme zamanlarında anlamlı farklılık bulunmuştur. ( $F=5.449, p<.001)$. Spor deneyimi 1 (bir) yıl olan öğrencilerin, spor

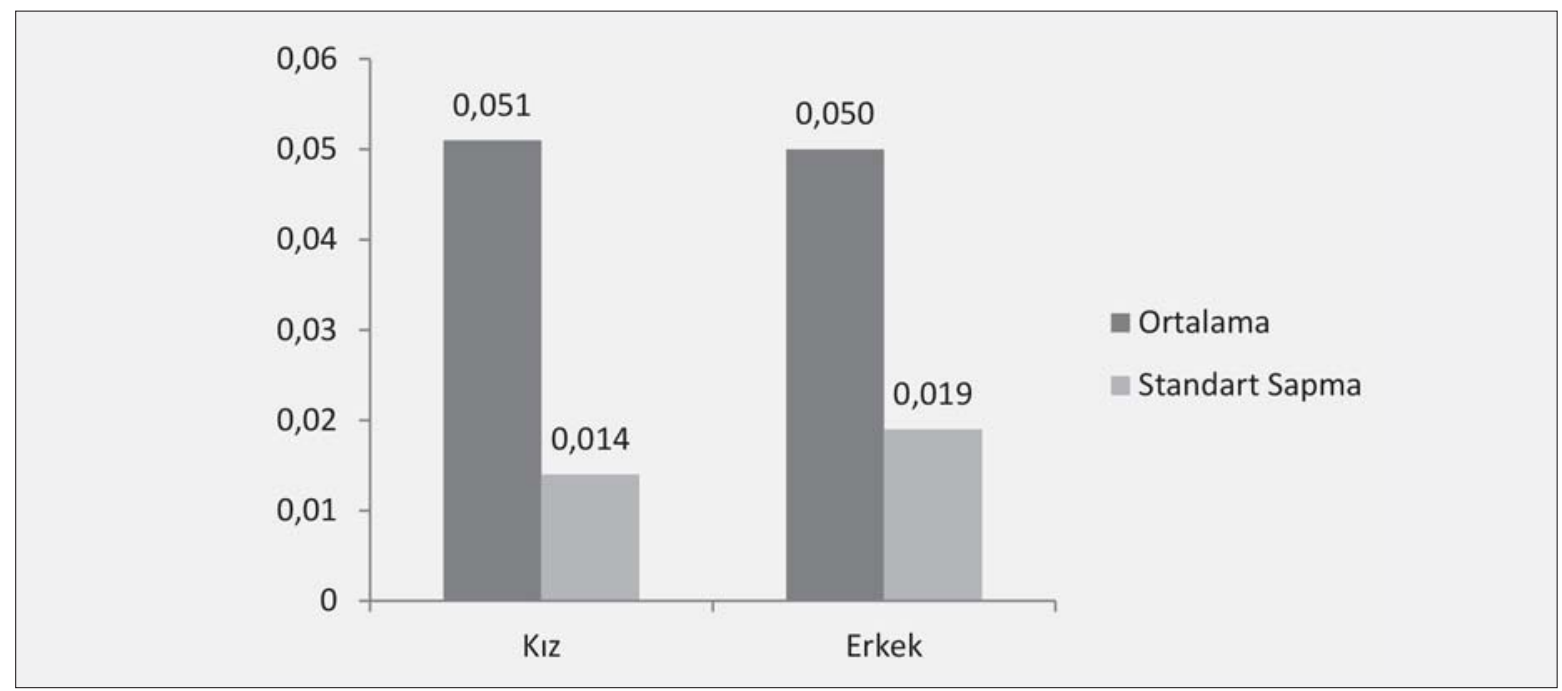

Grafik 2. Araştırmaya katılan tüm kız ve erkek öğrencilerin sezinleme zamanı ortalama (sn) ve standart sapma değerleri

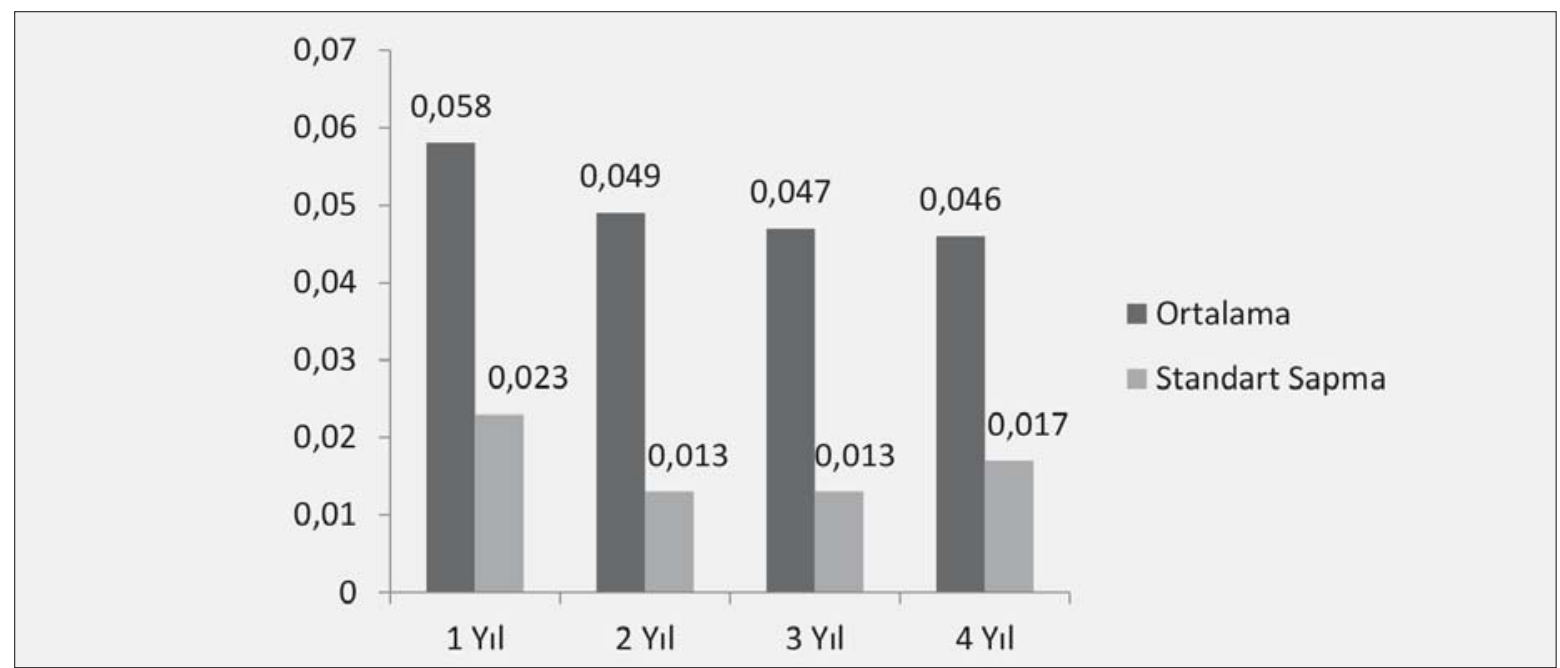

Grafik 3. Araştırmaya katılan öğrencilerin spor deneyim yılına göre sezinleme zamanı ortalama (sn) ve standart sapma değerleri 


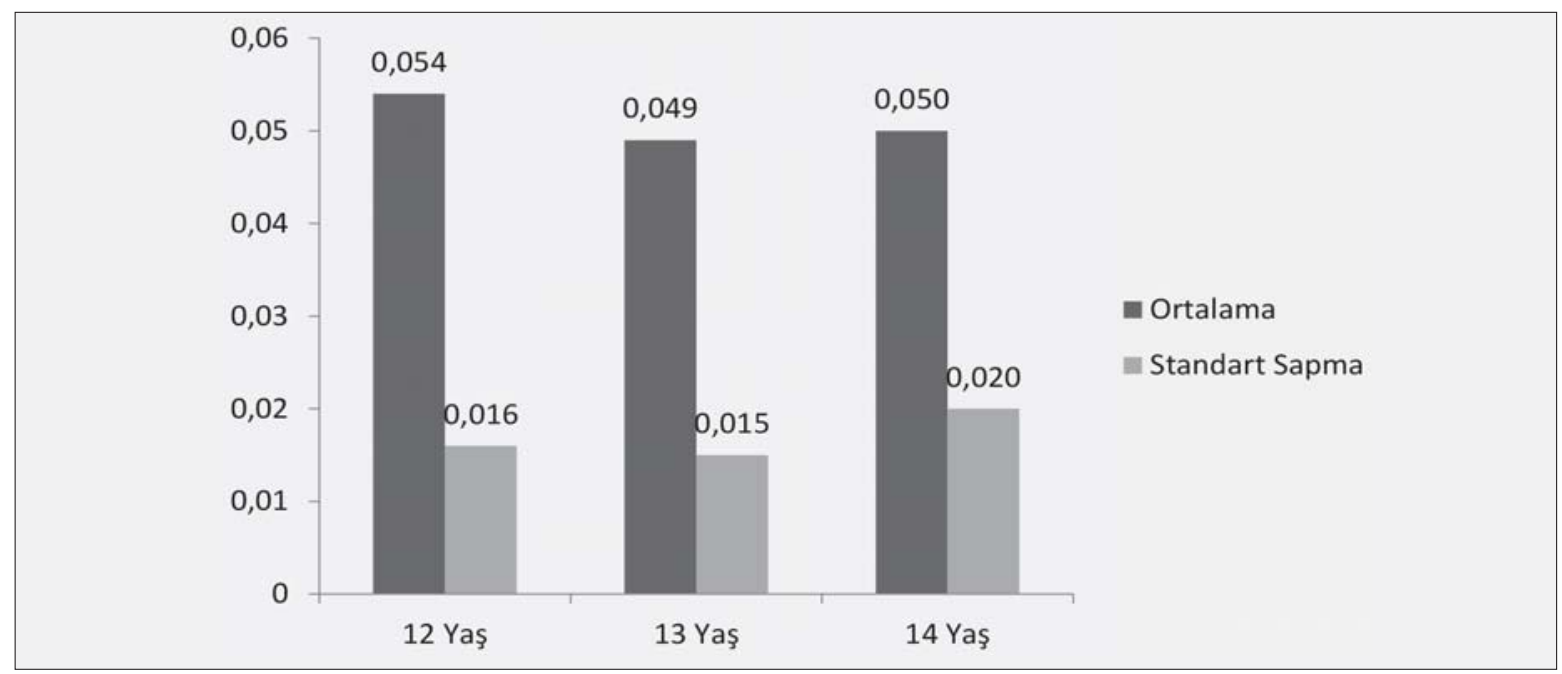

Grafik 4. Araştırmaya katılan öğrencilerin yaşa göre sezinleme zamanı ortalama (sn) ve standart sapma değerleri

deneyimi 2 (iki), 3 (üç) ve 4 (dört) yıl olan öğrencilere göre istatistiksel olarak daha uzun sezinleme zamanına sahip oldukları bulunmuştur.

Öğrencilerin yaşa göre sezinleme zamanı ortalama (sn) ve standart sapma değerleri Grafik 4'te verilmiştir.

Yaşı 12 (oniki) olan öğrencilerin sezinleme zamanları ortalaması 0.054 sn, 13 (onüç) olan öğrencilerin sezinleme zamanı ortalamaları 0.049 sn, 14 (ondört) olan öğrencilerin sezinleme zamanı ortalamaları 0.050 olarak tespit edilmiştir. Yapılan istatistik analiz sonucunda, yaşa göre öğrencilerin sezinleme zamanları arasında anlamlı farklılık bulunmamıştır ( $F=1.235, p>.05)$.

\section{TARTIŞMA}

Yapılan çalışmanın amacı takım sporu (basketbol-hentbol) ve bireysel spor (badminton-masa tenisi) yapan 7-8. Sınıf öğrencilerinin sezinleme zamanlarının incelenmesidir. Bu genel amaç doğrultusunda; takım sporu yapanlarla bireysel spor yapanlar arasında farkın olup olmadığı, takım sporu yapanlarla bireysel spor yapanların sezinleme zamanında cinsiyete göre fark olup olmadığı, spor deneyiminin sezinleme zamanına etkisinin olup olmadığını ve son olarak yaşın sezinleme zamanına etkisi olup olmadığı tespit edilmeye çalışılmıştır.

Özellikle nesne ile oynanan (topla oynanan) sportif etkinlikler içerisinde karşılaşılabilecek muhtemel pozisyonların daha önceden çalışılarak müsabakaya hazırlanılması, sezinleme za- manı performansını olumlu yönde etkileyebilir. Açık beceri performansında önemli süreçlerden biri ve spor başarısına katkısı olan hareketli nesnenin sezinlenmesidir (Coker, 2004).

$\mathrm{Bu}$ çalışmada toplanan verilerin analizi sonucunda; bireysel spor (Badminton-Masa Tenisi) yapan öğrencilerin, takım sporu yapan (Basketbol-Hentbol) öğrencilere göre daha iyi sezinleme zamanına sahip oldukları bulunmuştur.

Literatürdeki çalışmalara bakıldığında, özellikle bireysel sporlar ile takım sporları incelemesi/karşılaştırması yapılmadığı görülmektedir. Bunun yanında literatürdeki çalışmalar; aktif ve üst düzey spor yapanlar (Ak ve Koçak, 2010; Akpınar ve diğ., 2012; Poliszczuk ve Mosakowska, 2009; Söğüt ve diğ., 2009; Williams, 2000), aktif olarak spor yapanlarla spor yapmayanlar (Brady, 1996; Dede, 2010; Savelsbergh ve diğ., 2002) veya aktif spor yapanlarla spora yeni başlayanların incelendiği/karşılaştırıldığı (Kioumourtzoglou ve diğ., 1998; Lyons ve diğ., 2008; Mori ve diğ., 2002) görülmektedir.

Bireysel sporcularla çalışan Mori ve diğ. (2002), Poliszczuk ve Mosakowska (2009) ve takım sporcuları ile çalışan Kioumourtzoglou ve diğ. (1998), Williams L. (2000), Lyons, ve diğ. (2008) çalışmalarında, spor yapanların spor yapmayanlara göre daha iyi sezinleme zamanına sahip olduklarını bulmuşlardır.

Knoblich ve Jordan (2003) takım sporcularında kendi arkadaşının durumu, kişinin karar 
vermesini geciktirebileceğini, çünkü bireysel spor yapanlar hareketleri kişisel olarak yaptıklarından dolayı, hareketlerini rahatlıkla içsel olarak kontrol edebileceklerini, bireylerin ise, grupla hareket edince, bireysel hareketlerindeki koordineli davranışları rahatlıkla sergilemesinin zorlaşacağını ifade etmişlerdir. Bu araştırma sonucunda bulunan bireysel spor yapan öğrencilerin sezinleme zamanlarının takım sporu yapanlara göre daha iyi olması, Knoblich ve Jordan (2003)'nın araştırma sonuçları ile tutarlı olabileceği düşünülmektedir.

Bunlara ek olarak, Poliszczuk ve Mosakowska (2009)'da ve Akpınar ve diğ. (2012)'de tenis ve badminton gibi, sporcuların birbirlerine çok yakın mücadele ettiği sporlarda algılama ve sezinleme zamanının çok önemli bileşenler olduğu ve üst düzey performans için gerekli olduğunu belirtmişlerdir. Akpınar ve diğ., (2012) yaptıkları çalışmada tutma ve vurma gerektiren sporlar arasında algısal parametrelerin incelenmesi gereğini de vurgulamışlardır.

Bireysel sporlarda oyuncular top oyunda olduğu süre içerisinde, sürekli olarak dikkat ve sezinleme gibi ve algısal yeteneklerini oyuna odaklamak ve oyun içerisinde karşılıklı aktif olarak mücadele zorundadırlar. Takım sporlarındaki oyuncular ise topa yakın oyuncular aktif iken, topa uzak oyuncular yarı aktif veya pasif konumda olabilmektedirler. Ayrıca bireysel sporlar için düzenlenen oyun alanı takım sporları için düzenlenen oyun alanlarına göre daha küçük alanlar olduğundan ve özellikle bireysel ve etkileşim gerektiren sporlarda (interaktif spor) oyuncuların daha iyi algısal becerilere dolayısıyla daha iyi sezinleme zamanına sahip olmaları gerektiği düşünülebilir (Davis ve diğ., 2000).

Bununla birlikte, badminton ve masa tenisi gibi bireysel sporlarda karşısındaki tek rakip ve karşılıklı birbirlerine gönderilen tek top sezinleme zamanını etkilerken, basketbol ve hentbol gibi takım sporlarında birden fazla rakibin ve birden fazla takım arkadaşının olması, sezinleme zamanı ve karar verme sürecini etkileyeceği tahmin edilmektedir. Yapılan çalışmadaki elde edilen sonuçlar bu düşünceleri destekler niteliktedir.

Poliszczuk ve Mosakowska (2009)'da yaptığı çalışmada, badminton oyuncularının, hentbol ve basketbol oyuncularına göre, toplam görüş aralığının daha geniş olduğunu tespit ederek, Badminton ve tenis gibi bireysel sporlarda performansı etkileyen algı ve sezinlemenin, ilk ve en önemli bileşenleri olduğunu ifade etmişlerdir. Bu çalışmadaki temel amaç olan takım sporu yapanlar ile bireysel spor yapanların sezinleme zamanlarının incelendiği durum ile ilgili elde edilen sonuçlar, literatürdeki sonuçlarla paralellik göstermekte olup, bu araştırma sonucu elde edilen bulguları destekler niteliktedir.

Bu çalışma kapsamında elde edilen bulgular, araştırma grubundaki tüm öğrenciler karşılaştırıldığında, cinsiyetin sezinleme zamanına istatistiksel olarak anlamlı derecede fark olmadığı yönündedir. Literatürde cinsiyetin sezinleme zamanına etkisinin incelendiği çalışmalara bakıldığında, Söğüt ve diğ. (2009)'da yaptıkları çalışma sonucunda 10 yaş grubundaki oyuncuların 8 yaş grubundakilere oranla ve erkek oyuncuların kadın oyunculara oranla sezinleme zamanı performanslarının daha başarılı olduğunu, yaşın ve cinsiyetin, sezinleme zamanı üzerinde etkisi olduğunu bulmuşlardır (Söğüt ve diğ., 2009). Kuhlman ve Beitel (1987)'de yaş, cinsiyet ve spor deneyiminin sezinleme zamanına olan etkisini 3 ve 9 yaş arasında orta ekonomik düzeyde olan çocuklar üzerinde araştırmış, sonuçta; spor deneyimleri artmaya başladığında ve sezinleme zamanı performansında tutarlılık gerektirdiğinde, cinsiyete göre farklılıklar olduğu bulunmuştur. Bu sonuca göre, deneyim arttıkça erkeklerin kadınlara göre daha tutarlı oldukları görülmüş, kadınlarla erkekler arasında fark bulmuşlardır (KuhIman ve Beitel, 1987). Cinsiyetlerin karşılaştırıldığı diğer bir çalışmada Dede (2010) müsabık genç tenis oyuncularının sezinleme zamanı performanslarını incelemiş, araştırma sonucunda 8-10 yaş grubu aktif spor yapan çocukların sezinleme zamanlarında anlamlı bir farkın ortaya çıkmadığını ifade etmiştir. Millslagle (2004) görsel keskinlik ve sezinleme zamanı üzerine yaptığı çaIsşmasında, görsel keskinlik açısından cinsiyetler arası fark bulurken, cinsiyetin sezinleme zamanına etkisinin olmadığını tespit etmiştir. Stadulis ve diğ. (1990)'da 5.5-10.1 yaşları arasındaki tenisçiler üzerine yapılan benzer bir çalışmada, sezinleme 
zamanı performansında cinsiyetler arasında bir farkın olmadığını ortaya koymuşlardır.

Overdorf ve diğ. (2004) sezinleme zamanı becerisi kazanımı ve hatırlamaya etkisi üzerine yaptıkları çalışmalarında, 15 kadın ve 15 erkekten oluşan 30 üniversite öğrencisi arasında cinsiyetler arasında etkisini incelemiş, cinsiyet açısından baktıklarında bu becerinin kazanımı sırasında farklılık çıkmamasına rağmen, hatırlama testinde erkeklerin kadınlara göre daha az hata yaptıklarını bulmuşlardır. Bu çalışmada ise tek bir ölçüm yapılmış ve hatırlama testi yapılmamıştır. Dolayısıyla alınan ölçümde cinsiyet açısından farklılık bulunmamıştır. Overdorf ve diğ. (2004)'te bulmuş olduğu sonuç, bu araştırmada ulaşılan sonuçları destekler niteliktedir.

Genel olarak literatürdeki cinsiyetin sezinleme zamanı üzerine etkisinin incelendiği çalışmalarda farklılık bulunması; yaş, branş, ve deneyimden kaynaklanıyor olabilir. Bunun yanında, erkeklerin kadınlara göre daha iyi sezinleme zamanına sahip olduklarını belirten çalışmalarda bunun sebebinin yapılan hareketin zorluk derecesinden kaynaklanıyor olabileceği belirtilmektedir (Sanders, 2011). Bu çalışmalar sonucunda, erkeklerin özellikle kolay olan becerilerde avantajlı oldukları, beceri zorlaştıkça kadın ve erkekler arasındaki farkılığın azaldığı tespit edilmiştir (Petrakis, 1985; Sanders, 2011). Bu araştırmada ise cinsiyet açısından farklılık bulunmamıştır.

Spor deneyimine göre, verilerin istatistiksel analizi sonucunda, öğrencilerin sezinleme zamanlarında anlamlı fark bulunmuştur. 1 (bir) yıldır spor yapanlarla, 2 (iki), 3 (üç) ve 4 (dört) yıldır spor yapanlar arasında anlamlı fark vardır. Spor deneyimi arttıkça, öğrencinin spor yaşı ilerledikçe sezinleme zamanı süresinin kısaldığı, antrenman yaşı arttıkça sezinleme zamanı ortalamalarında iyileşme meydana geldiği görülmüştür.

Kioumourtzoglou ve diğ. (1998) çalışmasında, deneyimli sporcuların birçok algısal sezinleme becerisinde deneyimsiz olanlara göre çok daha iyi performans gösterdiklerini belirtmiştir. Bunun yanında deneyimli sporcuların, orta seviyedeki sporculara göre daha iyi performans gösterdikleri ortaya çıkmıştır (McMorris, 2004). Mori ve diğ. (2002) yaptıkları araştırmada deneyimli olan sporcuların deneyimsiz olan sporculara göre daha doğru tahminde bulunduğunu ortaya koymuşlardır. Savelsbergh ve diğ. (2002) çalışmalarının sonucunda, deneyimli olan sporcuların sezinleme becerilerinin deneyimsiz olanlara göre daha iyi olduğunu tespit etmişlerdir. Kioumourtzoglou ve diğ. (1998) ise her sporun kendine ait özellikleri algısal yetenekleri güçlü bir şekilde etkilediği ve bunun da deneyimli sporcular ve deneyimi olmayan sporcular arasındaki farklılıklara neden olduğunu belirtmişlerdir. Lyons ve diğ. (2008) deneyimli oyuncuların egzersiz şiddeti ne olursa olsun sezinleme zamanı performanslarının değişmediği ancak deneyimsiz oyuncularda bu durumun aynı olmadığını belirlemişlerdir. Kuhlman ve Beitel (1987) her iki cinsiyetin spor tecrübelerine başladıktan 1-2 yıl içerisinde sezinleme zamanı performansı elde ettiklerini ifade etmektedir. Bu durum, bu çalışma kapsamında ortaya çıkan sonuçlar ile tutarlılık göstermektedir.

Coker (2004), antrenman yapmanın, rakibin bilgilerini, eğilimini ve onlara özgü davranışlarını belirleme yeteneğini geliştirdiğini ve bu gelişme tahmin edilebilecek olayları sezinlemeyi iyileştirip gerekli davranışları önceden hazırlama yeteneği oluşturduğunu ifade etmiştir (Akt. Söğüt ve diğ., 2009, s. 4'te belirtildiği gibi). Rudisill ve Jackson (1992) ise, sezinleme zamanının sporcunun yaşından ve antrenman sayısından etkilenebileceğini belirtmişlerdir. Williams (1985) hataların deneyimle birlikte paralel olarak azaldığını tespit etmiştir. Deneyimin etkisini araştıran çalışmalarda genel olarak deneyimli sporcuların daha iyi bir sezinleme zamanına sahip oldukları bulunmuştur (Ripoll ve Latiri, 1997). Konu ile ilgili kaynaklar incelendiğinde aktif, deneyimli ve üst düzey spor yapanlarla spora yeni başlayanlar arasında sezinleme zamanlarında anlamlı farklar ortaya çıkmıştır. Spora yeni başlayan sporcular kendi karar verme süreçlerini etkileyecek, daha iyi karar vermelerini sağlayacak rakibin hareketlerindeki gereksiz ipuçlarına odaklanırken, deneyimli sporcuların ise daha bilgi verici, sezinleme zamanı performanslarını artırıcı ipuçlarına odaklandıkları görülmüştür (Mori ve diğ., 2002; Savelsbergh ve diğ., 2002). 
Antrenmanlar ve maç sayısının artması yapılan sporun temel bilgisini artırarak üstün sezinleme zamanı performansı elde edilmesini sağlar (Mori ve diğ., 2002). Bu çalışmada elde edilen veriler literatürdeki çalışmalarla paralellik göstermektedir. Dolayısıyla spor deneyiminin artması sezinleme zamanını olumlu yönde etkilemektedir.

Yapılan istatistiksel analiz sonucunda yaşlar arası anlamlı fark bulunmamıştır. Başka bir deyişle, yaşın araştırma grubunun sezinleme zamanı performansı üzerinde etkisinin olmadığı görülmüştür. Söğüt ve diğ. (2009) 8-10 yaş grubu elit tenis oyuncuları üzerinde yaptıkları çalışmada, 10 yaş grubundaki çocukların, 8 yaş grubundaki çocuklara oranla sezinleme zamanlarının daha başarılı olduğunu tespit etmişlerdir. Benzer çalışmalarla Kuhlman ve Beitel, (1987) ve Ak ve Koçak (2010) da yaşın sezinleme zamanı üzerine etkisini tespit etmişlerdir.

Gelişim Psikologları 3 yaşındaki çocukların, topun ebadı ve rotası ne olursa olsun topu yakalamak için sürekli aynı tekniği kullanmaya çalıştıklarını göstermişlerdir. Yaş ilerledikçe (5 yaş ve üstü) ve deneyim kazandıkça topun rotası ve konumuna bağlı olarak kullanılan teknikte de değişiklikler olduğu görülmüştür (McMorris, 2004).

Yaşla ilgili yapılan çalışmalarda ise; yaşla birlikte sezinleme zamanı performansının arttığı, diğer bir deyişle yapılan hataların deneyimle birlikte paralel olarak azaldığı görülmüştür (Williams K. , 1985). Dede (2010) 8-10 yaş grubu aktif spor yapan tenis oyuncularında yaptığı çalışmasında yaşın sezinleme zamanına etkisinin olmadığını tespit etmiştir.

Ortaya çıkan bu sonuçlar bu araştırmada elde edilen sonuçlarla karşılaştırıldığında Söğüt ve diğ. (2009), Kuhlman ve Beitel (1987) ve Ak ve Koçak (2010) ile benzerlik göstermezken, Dede (2010) ile benzerlik göstermektedir. Bu durumun çalışmaya katılan öğrencilerin, yıllık antrenman sayısı, süresi (yoğunluk) ve kalitesinden kaynaklanıyor olabileceği düşünülmektedir.

\section{SONUÇ ve ÖNERILER}

Bu çalışma sonucunda, bireysel spor (badminton ve masa tenisi) yapan öğrencilerle, takım sporu (basketbol ve hentbol) yapan öğrenciler karşılaştırılmış, bireysel spor yapan öğrencilerin sezinleme zamanlarının daha iyi olduğu bulunmuştur.

Literatürde, sezinleme zamanının cinsiyetler arasındaki farka bakıldığı çalışmalarda farklı sonuçlar olmasına rağmen, bu çalışmada cinsiyetler arası fark çıkmamıştır.

Sezinleme zamanı, spor yılı ve antrenman yaşı arttıkça iyileşmektedir. Yaşla birlikte sezinleme zamanı performansı artmakta, yapılan hatalar deneyimle birlikte paralel olarak azalmaktadır. 1 (bir) yıl spor yapan öğrencilerle, 2 (iki), 3 (üç) ve 4 (dört) yıldır spor yapanlar arasında anlamlı farklılık bulunmuştur. İlk yıldan itibaren sezinleme zamanında kazanım olmuştur.

Bu araştırmadaki diğer bir sonuç da, yaşın sezinleme zamanı üzerinde etkisi olmadığıdır.

Öğrenciler üzerinde yapılacak çalışmalarda minikler, küçükler, yıldızlar ve gençler kategorilerinde toplanacak veriler incelenerek/karşılaştırılarak daha kapsamlı ve genel anlamda daha ayrıntılı bilgi sahibi olunabilir.

Bu araştırmada bireysel sporlardan badminton ve masa tenisi, takım sporlarından basketbol ve hentbol seçilmiştir. Farklı branşlar üzerinde de sezinleme zamanı performansı incelenebilir. Futbolda mevkiler arası farkın olup olmadığı, kalecilerin sezinleme zamanı performanslarının kendi genel performanslarına etkisi incelenebilir. Aynı mantıkla basketbol, hentbol gibi branşların da mevkiler arası sezinleme zamanı performansları incelenebilir.

Bu araştırmada veri toplarken cihazın hızı 2 m/sn olarak tercih edilmiştir. Değişik hızlarda ölçümler yapılabilir (düşük-orta-yüksek).

Yaşın, sezinleme zamanına etkisinin olup olmadığının tespiti için daha geniş yaş aralığı ve daha fazla sayıda denek üzerinde çalışma yapılabilir. Son olarak, baskın el ile baskın olmayan el karşılaştırılması yapılabilir.

\section{Yazıșma Adresi (Corresponding Address):}

Öğretmen Mehmet Kadir Akbulut Kanuni Sultan Süleyman Ortaokulu, Belen, Hatay E-posta: mehmetkadirakbulut@gmail.com Telefon No:05497785160 


\section{KAYNAKLAR}

1. Ak E, \& Koçak S. (2010). Coincidence-anticipation timing and reaction time in youth tennis and table tennis player. Perceptual and Motor Skills, 879-887.

2. Akpınar S, Devrilmez E, Kirazcı S. (2012). Coincidenceanticipation timing requirements are different in racket sports. Perceptual \& Motor Skills: Exercise \& Sport, 581593.

3. Brady F. (1996). Anticipation of coincidence, gender, and sports classification. Perceptual \& Motor Skills, 82, 227-239.

4. Coker AC. (2004). Motor Learning and Control for Practitioners. New York: Mcgraw Hill.

5. Davis B. et al. (2000) The Nature and classification of skill. In: Physical Education and the study of sport. 4th ed. Spain: Harcourt Publishers, p. 284-285.

6. Dede M. (2010). Müsabık Genç Tenis Oyuncularının Sezinleme Zamanı Performanslarının İncelenmesi. Yüksek Lisans Tezi, Sakarya Üniversitesi, Sosyal Bilimler Enstitüsü, Sakarya.

7. DelVillar F, Gonzalez LG, Iglesias D, Moreno MP, Cervello EM. (2007). Expert-novice differences in cognitive and execution skills during tennis competition. Perceptual and Motor Skills, 104, 355-365.

8. Kioumourtzoglou E, Kourtessis T, Michalopoulou M, Derri V. (1998). Differences in several perceptual abilities between experts and novices in basketball volleyball and water polo. Perceptual and Motor Skills, 899-912.

9. Knoblich G, Jordan JS. (2003). Action coordination in groups and Individuals: Learning anticipatory control. Journal of Experimental Psychology: Learning, Memory, and Cognition, Vol. 29, No. 5, 1006 -1016.

10. Kuhlman JS, Beitel PA. (1987). Pattern of relationships of coincidence anticipation with age, gender, and depth of sport experience. Annual Conference of the North American Society for the Psychology of Sport and Physical Activity. Vancouver, British Columbia, Canada.

11. Lyons M, El-Nakeeb Y, Nevill A. (2008). Postexercise coincidence anticipation in expert and novice Gaelic games players: the effects of exercise intensity. European Journal of Sport Science, 205-216.

12. Magill R. (2004). Motor learning: concepts and applications. New York: Mcgraw Hill.

13. McMorris T. (2004). Acquisition and Performance of Sports Skills. West Sussex, England: JohnWiley \& Sons Ltd.

14. Merwe TM., Randt RD. (1999). Validation of a laboratory coincidence-anticipation timing test. South African Journal for Research in Sport, Physical Education \& Recreation, 21, 93-105.

15. Millslagle D. (2004). Coincidence anticipation and dynamic visual acuity in young adolescents. Perceptual and Motor Skills, 99, 1147-1156.

16. Mori S, Ohtni Y, Imanaka K. (2002). Reaction times and anticipatory skills of karate athletes. Human Movement Science, 213-230.
17. Overdorf V, Schweighardt R, Stephen J, McGrath R. (2004). Mental and physical practice schedules in acquisition and retention of novel timing skills. Perceptual \& Motor Skills, 51-63.

18. Petrakis E. (1985). Sex differences and specificity of anticipation of coincidence. Perceptual and Motor Skills, 61, 1135-1138.

19. Poliszczuk T, Mosakowska M. (2009). Interreactions of peripheral perception and ability of time-movemet anticipation in high class competitive badminton players. Studies in Physical Culture and Tourism.

20. Ripoll H, Latiri I. (1997). Effect of expertise on coincident-timing accuracy in a fast ball game. Journal of Sports Science, 15, 573-580.

21. Rowe RM, McKenna FP. (2001). Skilled anticipation in real-world tasks: measurement of attentional demands in the domain of tennis. Journal of Experimental Psychology, 60-67.

22. Rudisill ME, Jackson AS. (1992). Lab Manual-Theory and Application of Motor Learning. Onalaska, Texas, USA: MacJ-R Publishing Company.

23. Sanders G. (2011). Sex differences in coincidenceanticipation timing (CAT): A review. Perceptual \& Motor Skills, 61.

24. Savelsbergh GJ, Williams AM, Van Der Kamp J. (2002). Visual search, anticipation and expertise in soccer goalkeepers. Journal of Sports Science, 279-287.

25. Schmidt R, Lee T. (2005). Motor Control and Learning: A Behavioral Emphasis. Human Kinetics.

26. Söğüt M, Ak E, Koçak S. (2009). Coincidence timing accuracy of junior tennis players. Hacettepe Journal of Sport Science, 1-5.

27. Stadulis RE, Eidson T, LeGant N. (1990). Viewing position and eye-hand preference effects upon anticipation of coincidence. / Influence de la position $d$ ' attente, de preference oculaire et manuelle sur la performance a une tache $d$ ' anticipation coincidence. Perceptual \& Motor Skills, 339-350.

28. Tenenbaum G, Sar-el T, Bar-eli M. (2000). Anticipation of ball location in low and high-skill performers: A developmental perspective. Psychology of Sport and Exercise, 1, 117-128.

29. Williams AM, Starkes J. (2002). Cognitive Expertise And Performance in Interceptive Actions. Newyork: Routledge.

30. Williams A, Davids K, Williams J. (2000). Visual Perception and Action in Sport. New York: Routledge.

31. Williams K. (1985). Age differences on a coincident anticipation task influence of stereotypic or preferred movement. Journal of Motor Behaviour, 17, 389-4.

32. Williams L. (2000). Coincidence timing of a soccer pass: effects of stimulus velocity and movement distance. Perceptual and Motor Skills, 39-52. 